\title{
Do we need more genetic counselling in pediatric endocrine diseases?
}

\section{Eun-Jung Rhee}

Division of Endocrinology and Metabolism, Department of Internal Medicine, Kangbuk Samsung Hospital, Sungkyunkwan University School of Medicine, Seoul, Korea

Received: September 23, 2021

Revised: September 26, 2021

Accepted: September 28, 2021

Corresponding author:

Eun-Jung Rhee

Division of Endocrinology

and Metabolism, Department

of Internal Medicine,

Kangbuk Samsung Hospital, Sungkyunkwan University School of Medicine, 29 Saemunan-ro, Jongno-gu, Seoul 03181, Korea Tel: +82-2-2001-2485

E-mail: hongsiri@hanmail.net
This is an Open Access article distributed under the terms of the Creative Commons Attribution Non-Commercial License (https:// creativecommons.org/licenses/ by-nc/4.0/).
The need for genetic counseling and education in healthcare is rapidly growing. According to a report from a pediatric emergency department, $18.6 \%$ of patient visits were associated with previously diagnosed or suspected genetic disorders [1]. The authors concluded that more genetic counseling and referral to genetics experts would facilitate better diagnosis and treatment of these children, in many of whom earlier diagnosis would have resulted in better prognosis.

In this issue of Precision \& Future Medicine, three review articles were published on pediatric endocrine diseases considering their genetic aspects. Lee et al. [2] wrote a review article on genetic etiologies of central precocious puberty (CPP). As the prevalence of obesity in children markedly increases, the age of menarche tends to be younger, the prevalence of precocious puberty is higher in obese children, and the prevalence of CPP tends to be higher in Korean children according to the Korean national database [3]. CPP accounts for $50 \%$ to $80 \%$ of the variation in puberty initiation with female preponderance [4,5]. Although the time of puberty initiation shows high inheritability and genetic factors play a crucial role in CPP development, few genes have been identified: KISS1, KISS1R, MKRN3, and DLK1 are the four monogenic genes identified. Although the author suggested the requirement for genetic studies in patients suspected to have CPP, it is somewhat unsatisfactory that the author did not suggest how to expand the genetic testing in these suspected children or what to do in patients with confirmed genetic abnormality.

In another review article by Kwon and Kim [6], the authors reviewed the clinical aspects of congenital hypogonadotropic hypogonadism $(\mathrm{CHH})$ and its treatment. $\mathrm{CHH}$ is a very rare disease with a female predominance and is characterized by absent or incomplete sexual development and/or infertility due to gonadotropin-releasing hormone deficiency. This article comprehensively explains the clinical aspects and sex development from infancy to puberty and describes the candidate genes at different stages of development. Finally, the authors address different treatment goals in different developmental stages. The authors conclude the article by emphasizing the importance of a profound understanding of normal development for the appropriate diagnosis and treatment of $\mathrm{CHH}$.

The last review article by Kang et al. [7] is on monogenic diabetes mellitus (DM). Monogenic DM is mainly caused by a defect in a single gene that is associated with $\beta$-cell function or insulin action, and accounts for $<5 \%$ of all pediatric diabetes cases [8]. The main categories of monogenic diabetes include neonatal DM, maturity-onset diabetes of the young, and syndromic diabetes. This article describes different types of monogenic diabetes with known genetic causes and clinical implications in association with the genes involved, since some types of monogenic diabetes 
respond to specific oral hypoglycemic agents such as sulfonylurea. The authors emphasize the importance of precise diagnosis of monogenic diabetes for optimized treatment and for understanding the clinical course and familial recurrence risk.

From these three review articles, the readers will be able to learn more about relatively rare but important pediatric endocrine diseases with genetic causes, and will have the notion that a clinician's suspicions and referral for genetic testing are extremely important in some patients we see daily in the clinic, for better prognosis and survival.

\section{CONFLICTS OF INTEREST}

No potential conflict of interest relevant to this article was reported.

\section{ORCID}

Eun-Jung Rhee https://orcid.org/0000-0002-6108-7758

\section{REFERENCES}

1. Kumar P, Radhakrishnan J, Chowdhary MA, Giampietro PF.
Prevalence and patterns of presentation of genetic disorders in a pediatric emergency department. Mayo Clin Proc 2001;76:777-83.

2. Lee HS. Genetic etiologies of central precocious puberty. Precis Future Med 2021;5:117-24.

3. Kim YJ, Kwon A, Jung MK, Kim KE, Suh J, Chae HW, et al. Incidence and prevalence of central precocious puberty in Korea: an epidemiologic study based on a national database. J Pediatr 2019;208:221-8.

4. Dvornyk V, Waqar-ul-Haq. Genetics of age at menarche: a systematic review. Hum Reprod Update 2012;18:198-210.

5. Palmert MR, Hirschhorn JN. Genetic approaches to stature, pubertal timing, and other complex traits. Mol Genet Metab 2003;80:1-10.

6. Kwon A, Kim HS. Congenital hypogonadotropic hypogonadism: from clinical characteristics to genetic aspects. Precis Future Med 2021;5:97-105.

7. Kang E, Chung LY, Kim YJ, Oh KE, Rhie YJ. Monogenic diabetes mellitus and clinical implications of genetic diagnosis. Precis Future Med 2021;5:106-16.

8. American Diabetes Association. 2. Classification and diagnosis of diabetes: standards of medical care in diabetes2021. Diabetes Care 2021;44(Suppl 1):S15-33. 